\title{
Entre a Arte e o Sentido: a Matemática por trás das biojoias
}

\author{
Sandra Cobalchini Lima \\ Carmem Lucia Artioli Rolim
}

\begin{abstract}
Resumo: Este estudo trata do conceito de sentido, em seu caráter social e coletivo, a partir da produção artesanal de biojoias por um grupo de artesãs e do raciocínio matemático por trás dela. $O$ estudo parte de reflexões trabalhadas em uma dissertação de mestrado, apresentadas na $3^{\text {a }}$ Reunião Regional da Associação Nacional de Pós-Graduação e Pesquisa em Educação da Região Norte e ampliadas após o encontro. A organização teórica e metodológica do artigo foi pautada na perspectiva Histórico-Cultural, tratando-se de uma pesquisa qualitativa. As análises parciais permitem assegurar que a matemática não se restringe à compreensão do meramente exato ou racional, mas é uma construção da humanidade constituída de sentidos que conecta natureza e sociedade.
\end{abstract}

Palavras-chave: Artesãs. Biojoias. Matemática. Sentidos.

Sandra Cobalchini Lima Mestranda em Educação pela Universidade Federal do Tocantins (UFT) campus Palmas. Professora da Rede

Estadual da Bahia, Luís Eduardo Magalhães, BA, Brasil.

(1D) https://orcid.org/0000-0003-0623-3529 $\bowtie$ sandracobalchini@mail.uft.edu.br

Carmem Lucia Artioli Rolim Doutora em Educação pela Universidade Metodista de Piracicaba (UNIMEP). Professora do Programa de PósGraduação em Educação da Universidade Federal do Tocantins (UFT), Palmas, TO, Brasil.

http://orcid.org/0000-0003-4045-7964

$\triangle$ carmem.rolim@mail.uft.edu.br

Recebido em 15/04/2021 Aceito em 13/05/2021

Publicado em 21/08/2021

\section{Between Art and Meaning: the Mathematics behind bio-jewelry}

Abstract: This study deals with the concept of meaning, in its social and collective character, based on the handmade production of bio-jewelry by a group of female artisans and the mathematical reasoning behind it. The study is based on reflections developed in a master's thesis presented at the 3rd Regional Meeting of the Brazilian Association of Graduate Studies and Research in Education of the Northern Region and expanded after the meeting. The theoretical and methodological organization of the article was based on the Cultural-Historical perspective, being a qualitative research. The partial analyses allow us to assure that mathematics is not restricted to the understanding of the merely exact or rational, but is a construction of humanity made up of meanings that connect nature and society.

Keywords: Artisans. Bio-jewelry. Mathematics. Senses.

\section{Entre el Arte y el Significado: las Matemáticas por detrás de las biojoyas}

Resumen: Este estudio aborda el concepto de significado, en su carácter social y colectivo, a partir de la producción artesanal de bio-joyas por parte de un grupo de mujeres artesanas y el razonamiento matemático que lo sustenta. El estudio parte de reflexiones trabajadas en una tesis de maestría, presentada en el III Encuentro Regional de la Asociación Brasileña de Posgrado e Investigación en Educación de la Región Norte y ampliada después del encuentro. La organización teórica y metodológica del artículo se basó en la perspectiva histórico-cultural, siendo una investigación cualitativa. Los análisis parciales permiten asegurar que las matemáticas no se limitan a la comprensión de lo meramente exacto o racional, sino que son una construcción de la humanidad constituida de sentidos que conecta naturaleza y sociedad.

Palabras clave: Artesanas. Biojoyas. Matemática. Sentidos. 


\section{Introdução}

Muitos são os questionamentos sobre as formas de como os seres humanos constroem sentidos sobre a sua existência. Vale citar aqui as obras de Lev Vigotski ${ }^{1}$, exemplos dos esforços do autor em torno de processos eminentemente humanos, especialmente os manuscritos " 0 significado histórico da crise da psicologia" e "Pensamento e Linguagem", os quais evidenciam o conceito de sentido.

No centro desse debate, está a questão que Vigotski (2001) busca responder: o que especificamente torna o ser humano "humano" a partir da sua própria condição? Nessa direção, Góes e Cruz (2006) afirmam que o desenvolvimento da consciência humana, entendida como construções de significados e sentidos subjetivos, tem como princípio explicativo as relações sociais. Em outras palavras, a consciência se forja socialmente.

Ao evidenciar a relação do desenvolvimento da consciência humana com o social, Vigotski avança introduzindo o conceito de significado. Assim, o autor, em texto publicado originalmente em 1934, apontava que

[a] palavra desprovida de significado não é palavra, é um som vazio. Logo, o significado é um traço constitutivo indispensável da palavra, [...] Generalizações e significado da palavra são sinônimos. [...] Consequentemente, estamos autorizados a considerar o significado da palavra como um fenômeno do pensamento (VIGOTSKI, 2001, p. 398).

Dessa maneira, os significados se modificam e se desenvolvem desde o nascimento do indivíduo até seu desenvolvimento final, pois "o significado é inconstante. Modifica-se no processo de desenvolvimento. Modifica-se também sob os diferentes modos de funcionamento do pensamento. É antes uma formação dinâmica que estática" (VIGOTSKI, 2001, p. 407).

Segundo Moura et al. (2010), o predomínio dos sentidos sobre os significados seria uma das maiores ilustrações da abundância do significado, cujo conceito de sentido aparece no texto vigotskiano "Pensamento e Palavra" (VIGOTSKI, 2001). Para o pensador russo,

o sentido de uma palavra é a soma de todos os fatos psicológicos que ela desperta em nossa consciência. Assim, o sentido é sempre uma formação dinâmica, fluida, complexa, que tem várias zonas de estabilidade variada. O significado é apenas uma dessas zonas do sentido que a palavra adquire no contexto de algum discurso e, ademais, uma zona mais estável, uniforme e exata (VIGOTSKI, 2001, p. 465).

\footnotetext{
1 Lev Semynovich Vygotsky (1896-1934) nasceu em Orsha, pequena cidade perto de Minsk, a capital da Bielorrússia (região que se tornou independente em 1991 e atualmente chama-se Belarus). O nome Vigotski tem sido grafado de diferentes formas na literatura ocidental. Por ser a forma encontrada na maioria dos livros em língua portuguesa, em citações e referências, a grafia Vigotski será a utilizada nesta pesquisa (ALMEIDA, 2009)
} 
Os sentidos e os significados produzidos na consciência são internalizados e passam a constituir nossas concepções, representações, sentimentos, entendimentos, expectativas, frustrações. Isto é, eles passam a compor a realidade produzida por meio das experiências humanas.

Tendo o conceito de sentido como referencial fundante da discussão apresentada neste artigo, buscamos identificar os conhecimentos matemáticos implícitos na produção das biojoias. Ainda que a matemática se caracterize pelo formalismo e pela abstração, o conhecimento matemático encontra vigor nas interações entre o indivíduo e o meio.

O movimento que dialoga com a proposta é o de que a matemática pode ser entendida como um produto social, pois resulta da interação e necessidade entre as pessoas de uma mesma comunidade (SADOVSKY, 2010). Esse conceito de produto social liga-se ao de atividade humana, que é perpassado por uma condição social e historicamente marcada. Além de Vigotski, já mencionado, podemos citar os estudos de Davidov, o qual considera que a atuação criativa do ser humano modifica sua realidade.

Libâneo e Freitas (2017), descrevem como ocorre esse processo descrito por Davidov:

\begin{abstract}
[a] atividade humana é compreendida como um processo em que a realidade é transformada pela atuação criativa dos seres humanos, originalmente pelo trabalho e do qual derivam todos os demais tipos de atividade humana e material. Por meio da apropriação da experiência social e histórica, o sujeito individual reproduz em si mesmo a atividade coletiva, as formas histórico-sociais da atividade. Essa atividade coletiva realizada de forma externa converte-se em meios de atividade individual por meio do processo de interiorização (LIBÂNEO; FREITAS, 2017, p. 346).
\end{abstract}

Ademais, "o desenvolvimento mental de um indivíduo é, antes de tudo, o processo de formação de sua atividade, de sua consciência e, claro, de todos os processos mentais que as 'servem' (processos cognitivos, emoções, etc.)" (DAVYDOV apud LIBÂNEO; FREITAS 2017, p. 10 e 346). Assim, as diferentes formas de expressar a matemática necessária na atividade de produção das biojoias são oriundas de características próprias das artesãs. Características que estão carregadas de humanidade, necessidade e de intencionalidade, compondo os sentidos e significados próprios desses indivíduos participantes do estudo.

Frente a essas concepções, a matemática pode estar além da compreensão do meramente exato ou racional. Ela pode buscar um sentido que a conecta com a natureza e com a sociedade. Dessa forma, a matemática significada pelas mãos da artesã que manuseia as sementes do cerrado na produção das biojoias dialoga e transita com a matemática da razão. Nesse contexto, as artesãs, valorizando a riqueza natural e a cultura local do seu ambiente, expressam seus saberes e experiências de vida no artesanato das biojoias. Entende-se assim 
que a cultura está incluída "em todas as dimensões da sociedade, como um conjunto complexo e diferenciado de teias - de símbolos e significados - com as quais homens e mulheres criam entre si e para si mesmos sua própria vida social" (BRANDÃO, 1995, p. 86).

Nesse contexto, ressalta-se a importância da produção dos sentidos, uma vez que 0 enfoque principal do estudo será dado pelo viés da Educação Matemática. Ao contemplar a matemática sob essas lentes, podemos percebê-la como uma prática científica e uma linguagem. De acordo com Moura (2002) a matemática é considerada um elemento criado pelo homem para suprir suas necessidades de conhecer, compreender e agir sobre fenômenos naturais e segundo o autor, instituir relações humanas a partir uma linguagem com signos e regras próprias.

Dentro desse processo de reflexão, contemplando um caminho de possibilidades, 0 presente artigo tem a intenção de conceber uma compreensão sobre 0 entendimento do raciocínio matemático no espaço de construção da arte com biojoias. Composta por seis artesãs, a Associação Caliandra Artesãos do Cerrado e Agricultura Familiar abriga um espaço destinado à produção de biojoias produzidas a partir de materiais vindos da natureza, tais como sementes, fibra de babaçu, casca de coco, capim dourado, entre outros.

A compreensão que a artesã tem sobre a matemática, isto é, o sentido que ela dá à matemática na confecção de uma biojoia, é o objeto de estudo em questão. Ao confeccionar uma biojoia, a artesã desenha a peça mentalmente, risca e perfura sementes, faz incisões e pinta superfícies de um adorno, revelando na gênese dessa peça elementos de significação da matemática.

Ao imaginar uma biojoia, a artesã remete mentalmente à sua imagem, algo figurativo num primeiro momento. Na construção do artesanato, tal imagem não tem a intenção de um conteúdo matemático, mas revela um raciocínio matemático contextualizado de significados oriundos da construção social de cada artesã.

$\mathrm{Na}$ área da educação, em especial da educação matemática, pensar no raciocínio matemático das artesãs é desvelar uma matemática que se encontra implícita nas construções delineadas coletivamente. Essas construções são uma manifestação de ações sensíveis, que trazem sentidos e significados e se expressam em determinado contexto histórico e social.

Poucos estudos tematizam a relação da teoria vigotskiana em ambientes de artesanato com a matemática, tornando escassos o escopo literário pertinente ao tema. 


\section{Percurso metodológico: abrindo caminhos}

Iniciamos a caminhada metodológica com o objetivo de discutir o conceito de sentido envolvido no raciocínio matemático implícito na produção de biojoias pelo grupo de artesãs. Um caminhar que na trama dos questionamentos sobre o ensino da matemática, entrelaça-se a um processo repleto de sentidos e singularidades, apoiando-se nas contribuições da psicologia histórico-cultural

A ênfase metodológica do estudo está respaldada na abordagem qualitativa, caracterizada pela busca da descoberta e da compreensão, privilegiando a experiência criativa e 0 aspecto indutivo e respondendo a questões que refletem particularidades. $\mathrm{Na}$ abordagem qualitativa, o interesse está em conhecer a variável de estudo por meio do seu significado e do contexto em que ela se insere.

Recorremos assim à Minayo (2003, p. 16-18), que trata a pesquisa qualitativa como uma atividade da ciência que visa à construção da realidade, "trabalhando com o universo de crenças, valores, significados". Bogdan e Biklen (1994, p. 49) reiteram que o investigador se interessa, acima de tudo, por tentar compreender os significados que os participantes atribuem às suas experiências.

Com a finalidade de alcançar o objetivo proposto, a discussão teórica foi realizada mediante pesquisa bibliográfica, que corresponde à literatura cientifica que fomenta o diálogo com os dados coletados. Para Ruiz (2008, p. 58), a pesquisa bibliográfica trata do embasamento teórico da temática, que consiste no "exame dos materiais para levantamento e análise do que já se produziu sobre determinado assunto que assumimos como tema da pesquisa científica".

No que concerne a Demo (1995), dentro de uma exposição lógica, rigorosa, coerente e crítica de argumentação sobre um determinado tema, o pesquisador poderá desvelar sentidos através da pesquisa teórica, uma vez que haja delimitação prévia de corpus da literatura, mobilizando a bibliografia conforme a necessidade para construir a argumentação. Isso posto, para a análise de dados, focamos em duas categorias, que entendemos como centrais dentro do referencial teórico que assumimos.

Buscamos identificar o sentido da matemática e a apropriação² da cultura através das relações sociais. Ao assumirmos as Categorias de Análise, Bardin (1977) orienta que elas podem ser "rubricas ou classes, as quais reúnem um grupo de elementos sob um título

\footnotetext{
2 Entende-se, dentro do referencial teórico adotado, que o conceito de apropriação, seja aquele pelo qual o sujeito de forma socialmente significativa "reproduz em si as formas histórico-sociais da atividade" (DAVIDOV, 1988, p.11)
} 
genérico" (BARDIN, 1977, p. 117). Dessa forma, as Categorias de Análise tiveram como um pano de fundo a problemática do trabalho.

Para apontar esse percurso, o artigo inicialmente desvela a relação entre a matemática e a arte, demonstrando a importância desse enfoque para o desenvolvimento de pesquisas em Educação Matemática; apresenta em seguida uma revisão de literatura sobre o conceito de sentido na trama dos processos sociais e, na tentativa de revelar um possível raciocínio matemático e o sentido implícito nele, avançamos para as considerações finais.

\section{A matemática pelo sentido da arte e da sensibilidade}

No desenvolvimento da construção teórica perpassamos por duas formas de compreender a matemática, sendo que a primeira é a matemática como ciência, construída e formalizada ao longo da história. Para Fiorentini, esse foi um processo de construção sinuoso e difícil, pois ele

[é] obra de várias culturas e de milhares de homens e mulheres que, movidos pelas necessidades concretas, construíram coletivamente a matemática que conhecemos hoje. De fato, assim como todo conhecimento, a matemática é também um conhecimento historicamente em construção que vem sendo produzido nas e pelas relações sociais (FIORENTINI, 1994, p. 67).

Surgiram diferentes escolas de pensamento, na Filosofia da Matemática, que buscaram refletir sobre a natureza desse conhecimento, tais como o formalismo, logicismo e 0 intuicionismo, que delineiam uma visão mais absolutista da matemática. Santos (2014) descreve o surgimento de uma linha construtivista, valorizando o envolvimento humano na construção desse conhecimento.

Pensando em uma matemática mais ampla que une suas aplicações com as formas de pensar cotidianas, Skovsmose (2007, p. 47) cita exemplos nos quais podemos encontrar a matemática: na leitura automática do código de barras, na política de segurança do cartão de crédito, nas operações de sistemas, nas técnicas de construções de casas, nas vendas e compras de mercadorias, na leitura de um jornal com seus gráficos e informações. Conceitos aprendidos e usados a todo o tempo em nossa sociedade, mas nem sempre com o rigor da matemática formal.

Outra questão relevante é levantada por Fiorentini (1994), que assim como Skovsmose (2007), diferencia a tendência mais internalista (na qual os elementos necessários para se 
aprender matemática estão contidos no interior da própria matemática) daquelas que são mais externalistas (com a matemática como atividade humana). Dessa forma, na tendência externalista valoriza-se as abordagens que exploram a matemática não sistematizada que surge do artesanato, feira, agricultura, construção de casas; a leitura do mundo e as informações que fazem uso da matemática; a compreensão do significado histórico das ideias e a promoção de competências críticas.

Frente a essa forma de entender e aplicar a matemática, Read (1986) aponta para a compreensão da natureza da arte e da natureza humana como fatores primordiais para 0 entendimento também dos conceitos matemáticos. Assim, capacidades como imaginação, visualização, espontaneidade, sensibilidade tornam-se fundamentais para a compreensão da realidade e construção de conhecimentos matemáticos, já que

[a] compreensão da realidade na sua unidade exige, então, a movimentação das duas capacidades essenciais do ser humano, ambas necessárias, como veremos, para a constituição do conhecimento e até da própria realidade, considerando esta em seus aspectos tanto materiais quanto espirituais: a razão e a emoção, traduzidas no pensamento e a racionalidade a primeira, e na intuição e a sensibilidade à segunda. Ambas têm seu ápice na matemática e na arte respectivamente (CIFUENTES, 2010, p. 14).

Sendo parte das diferentes manifestações artísticas da comunidade em que se insere, a produção das biojoias pode ser considerada não uma aquisição superficial do pensamento, mas a superação de padrões racionais e o alcance da liberdade em processos que envolvem colaboração e interação. Assim, existe uma relação dialética entre indivíduo e sociedade por trás da confecção das biojoias, já que estamos diante de uma atividade humana que,

\begin{abstract}
quer considerada do ponto de vista individual, quer do ponto de vista social, exige um conhecimento, tão completo quanto possível, do mundo que o rodeia. Não basta conhecer os fenômenos: importa compreender os fenômenos, determinar as razões de sua produção, descortinar as ligações de uns com os outros [...]. Quanto mais alto for o grau de compreensão dos fenômenos naturais e sociais, tanto melhor o homem se poderá defender dos perigos que o rodeiam, tanto será seu domínio sobre a natureza e as suas forças hostis, tanto mais facilmente ele poderá realizar aquele conjunto de atos que concernem para a sua segurança e para o desenvolvimento da sua personalidade, tanto maior será, enfim, a sua liberdade (CARAÇA, 2005, p. 62).
\end{abstract}

A sensibilidade traduzida em arte é uma das habilidades a que os sentidos se submetem naturalmente, pois a arte evidencia o que os sentidos buscam em sua percepção intuitiva da forma, da harmonia e da experiência. De acordo com Gusmão (2013, p. 62), o homem amplia sua capacidade de observar, analisar, indagar, questionar, selecionar, ordenar, sentir, intuir, imaginar e criar com o exercício da arte e o fazer matemático, uma vez que podem ser 
consideradas fontes de conhecimento para a matemática. Dessa forma, as capacidades, como a espontaneidade e a liberdade de expressão, tão importantes na arte que estimulam o ser humano, favorecem também a compreensão da matemática, por meio de processos de visualização.

Concordamos com Rolim e Góes (2009, p. 513) ao evidenciarem a matemática como "uma construção cultural que orienta o indivíduo na relação com o meio". Por isso, conhecer significados e sentidos organizados por um determinado grupo social acerca desse processo contribui por desvelar determinantes que podem influenciar no desencadear das inúmeras ações dele decorrentes.

\section{0 conceito de sentido na trama dos processos sociais}

Os seres humanos, continuamente buscam sentido para o que fazem, na intenção de uma realização que assegure o entendimento do ato. Concordamos com Lopes et al. (2016) quando enfatiza que a busca do sentido ocorre na interação entre os sujeitos envolvidos, através de ações coletivas e que "por meio do outro o sujeito pode desenvolver-se; que as funções ainda não dominadas por ele poderão ser internalizadas; e que as formas coletivas precedem as individuais e constituem sua fonte de origem" (LOPES et al., 2016, p. 7)

Os processos que abordam sentidos perpassam a nossa vivência em sociedade, uma vez que abrangem "vias para que se admita a polissemia da linguagem e, consequentemente, para que se pense em múltiplas construções de sentidos" (BARROS, 2009, p. 179). Dessa forma, o estudo da produção de sentidos só pode ser realizado tomando por base a consideração do seu caráter social e coletivo, a partir da relação entre o indivíduo e o contexto no qual se insere. Isso implica considerar o que é dito pelo indivíduo e as condições de produção de seu discurso.

Quando se compreende algo que é relevante, potencializa-se a decisão em aprender significativamente, isto é, o que se aprende com sentido possivelmente será uma aprendizagem com significado. Bruner (2001) ao abordar os contextos culturais, afirma que o sentido que eles dão a aprendizagem origina seu significado, pois

[produzir] significados envolve situar encontros com o mundo em seus contextos culturais apropriados a fim de saber 'do que eles tratam'. Embora os significados estejam 'na mente', eles têm origem e sua importância na cultura na qual são criados (BRUNER, 2001, p. 16). 
Para Novak (1998), a criação de um novo conhecimento envolve um nível elevado de aprendizado significativo, pois ocorre quando o indivíduo possui uma estrutura organizada de conhecimento e um forte comprometimento para buscar novos significados.

Segundo Aguiar (2007), o indivíduo produz sentidos do vivido, daquilo que internaliza, compartilhando esses sentidos subjetivos em suas relações sociais. Esse processo transforma 0 social em subjetivo e isso é uma nova produção, que colocada no social, acaba por modificá-la.

Em seu livro O desenvolvimento do Psiquismo, Leontiev (1978) assume os termos significação ou significado social e sentido pessoal para o que chamamos de significado e sentido. Para o autor, significação é o reflexo da realidade e independe da vontade do indivíduo, ou seja, é a forma sob a qual nos apropriamos da experiência humana historicamente construída independentemente da relação individual ou pessoal que estabelece com ela. Ao nascer, encontramos um sistema de significações provisoriamente pronto, construído historicamente e apropriamo-nos dele tal como se apropria de um instrumento, precursor material da significação (LEONTIEV, 1978, p. 272).

Ainda em Leontiev (1978), o sentido, como fato psicológico, é uma interpretação pessoal da significação e, por isso, varia de pessoa para pessoa. É como um 'significado para mim'. Para Torisu (2018, p. 3), "a significação é algo mais ou menos pronto e mais ou menos parecido para um mesmo grupo em determinado momento histórico, ao passo que o sentido é pessoal e depende do percurso de vida de cada um". Concordamos com Asmolov (1984) quando diz que

\footnotetext{
[o] sentido pessoal representa o reflexo individualizado do mundo, que inclui a relação da personalidade com aqueles objetos pelos quais se desenvolve sua atividade e sua comunicação. As mais diversas manifestações da cultura, e mais amplamente, das relações sociais, assimiladas pelo sujeito no processo da interiorização das normas sociais, conceitos, papéis, valores e ideias percebidos por ele nos atos e ações de outras pessoas, podem adquirir para ele o sentido pessoal, se transformando em "significados para mim" (ASMOLOV, 1984 apud REY, 2007, p. 166).
}

Considerando que as ações de cada participante, conforme Asmolov (1984 apud REY, 2007), são mediadas por mecanismos necessariamente sociais, é certo que estas adquirem sentidos e significados múltiplos, dependendo de sua participação e de seu envolvimento na rede de relações, de forma que, pautada na perspectiva histórico-cultural, a investigação das participantes implica considerar as pessoas em suas atividades específicas, as ações que ali empreendem, as relações sociais estabelecidas, as condições sociais, históricas e econômicas do contexto e a maneira como significam - compreendem e aprendem - essa realidade. 
Dessa forma, os significados são compreendidos como construções elaboradas coletivamente em um dado contexto histórico, econômico e social. Já os sentidos são uma produção pessoal decorrente da apreensão individual dos significados coletivos nas experiências cotidianas.

\section{Tecendo Resultados}

As discussões possibilitam observar que o ser humano age e constrói a sua história em contextos específicos, conforme a perspectiva histórico-cultural. Isso evidencia 0 desenvolvimento humano, a construção da consciência e a matemática por meio de relações sociais mediadas por artefatos culturais.

Como o sujeito dá sentido a algo, podemos compreender como o grupo de artesãs significa a matemática na confecção da biojoia e quais sentidos atribuem a essa disciplina do saber, com base em seu caráter social e coletivo. Ainda que a matemática tenha formalismo e abstração, o conhecimento matemático encontra vigor nas interações entre indivíduo e meio. As diferentes formas de expressar a matemática, no contexto da produção das biojoias, são oriundas de características próprias das artesãs - carregadas de humanidade, necessidade e intencionalidade, compondo os sentidos e significados próprios desses indivíduos.

Frente a essas concepções, a matemática não se restringe a compreensão do meramente exato ou racional. Ela é uma construção da humanidade constituída de sentido de significação que conecta a natureza e a sociedade. Por meio de aspectos socialmente estruturados e definidos historicamente por meio de instrumentos culturais, a matemática significada pelas artesãs pode transitar pela matemática da razão quando ela proporciona ações criativas, ou seja, raciocínios matemáticos resultantes de uma percepção sensível, manifestada social e culturalmente pelo homem (FIALHO, 2013, p. 353). Isso amplia espaços de reflexão e pesquisa que envolvam a temática, incluindo conhecimentos teóricos sobre 0 assunto, e apontam novas formas de enxergar a matemática em uma perspectiva sociocultural.

Nesse contexto, repensar uma nova dimensão para a matemática e sua função na escola e no desenvolvimento do aluno faz-se necessário, uma vez que educadores matemáticos podem trabalhar não só 0 aspecto racional da matemática, mas também podem motivar 0 aspecto sensível da mesma, sem apartar o que é habitual na vida do aluno do que deve ser ensinado. 
Ademais, a experimentação matemática, assim como a estética são cognitivas, pois abarcam compreensão, racionalidade, aprendizagem e sentimentos, havendo inúmeras possiblidades de se aprender matemática a partir das características da arte. Mediante o fazer matemático aliado ao exercício da arte "o homem amplia sua capacidade de observar, indagar, analisar, questionar, selecionar, ordenar, associar, sentir, intuir, imaginar e criar" (GUSMÃO, 2013, p. 149).

Tanto a arte como a matemática apresentam aspectos epistemológicos como imaginação, intuição, criação e sensibilidade, que são fontes de conhecimento. No que concerne aos aspectos metodológicos, ressaltamos a espontaneidade e a liberdade de expressão na criação artística que favorecem a compreensão da matemática, por meio da visualização, ou seja, o "olhar matemático é o efeito de práticas visuais e o conhecimento matemático o suporte para a elaboração de verdades em torno de como se representa e se olha." (FLORES, 2016, p. 3). De certa forma, toda imagem "nos oferece algo para pensar: ora um pedaço do real para roer, ora uma faísca do imaginário para sonhar" (SAMAIN, 2012, p. 22). Assim espaço, distância, perspectiva, luz, volume, profundidade são enunciados incorporados em pensamentos matemáticos em um processo de criação, de invenção, de sensação.

\section{Conclusões}

Tendo como base a produção dos sentidos, ao retomar o objetivo deste artigo, no qual temos a intenção de identificar os conhecimentos matemáticos implícitos na produção das biojóias, evidenciamos, de maneira parcial, uma vez que a pesquisa se encontra em construção, que as artesãs atribuem sentidos a compreensão do que é a matemática, através da apropriação de elementos da cultura humana construída historicamente. Cada artesãs organiza suas ações, não a partir de uma experiência única, mas a partir de sua própria existência, o que possibilita que o sentido dado se sustente.

Estes dados fornecem pistas, ainda que sem conseguir generalizar para um cenário maior, que quando levado para o ensino da matemática, o saber matemático contido na produção das biojoias está indissociável aos sentidos que são atribuídos a ele, desde o momento da coleta do material para as biojoias nas veredas até sua produção artesanal. $A$ compreensão que a artesã faz da essencialidade do trabalho coletivo, faz com que elas se apropriem de situações que surgem no contexto do artesanato e permite que compartilhem 
ações e sentidos. Uma vez que cada artesã se apropria do conhecimento de forma coletiva, construída através de seu processo histórico, a educação pode ser assumida como um processo social, e não individual, ofertando-se entre sujeitos sensibilizados por objetivos comuns.

\section{Referências}

AGUIAR, Wanda Maria Junqueira. A pesquisa em psicologia sócio-histórica: contribuições para o debate metodológico. In: BOCK, A. M. B.; GONÇALVES, M. G. M.; FURTADO, O. (orgs.). Psicologia sócio-histórica: uma perspectiva crítica em psicologia. 3. ed. São Paulo: Cortez, 2007, p. 129-140.

ALMEIDA, Anne. Ludicidade como instrumento pedagógico. Belo Horizonte, jan. 2009. Disponível em: http://www.cdof.com.br/recrea22.htm. Acesso em: 5 mai. 2020.

ASMOLOV, Alexander. Lichnost kak predmet psikjologicheskovo isledavaniya [A personalidade como objeto da investigação psicológica]. Mosco: Izdatelstva Moskoskovo Universiteta, 1984.

BARDIN, Laurence. Análise de Conteúdo. Lisboa: Edições 70, 1977.

BARROS, João Paulo Perreira; PAULA, Luana Rêgo Colares de; PASCUAL, Jesus Garcia; COLAÇO, Veridiana de Fátima Rodrigues; XIMENES, Verônica Morais. O conceito de "sentido" em Vygotsky: considerações epistemológicas e suas implicações para a investigação psicológica. Psicologia \& Sociedade, 21 (2), p. 174-181, 2009.

BOGDAN Robert; BIKLEN Sari. Investigação qualitativa em educação. Porto: Porto Editora, 1994.

BRANDÃO, Carlos R. Em campo aberto. São Paulo: Cortez, 1995.

BRUNER Jerome. A Cultura da Educação. Porto Alegre: Artes Médicas, 2001.

CARAÇA, Bento J. Conceitos fundamentais da matemática. 6. ed. São Paulo: Grativa, 2005.

CIFUENTES, José Carlos. Do conhecimento matemático à educação matemática: uma "Odiséia Espititual". In: CLARETO, Sônia M.; DETONI, Adlai R. PAULO, Rosa M. (orgs). Filosofia, Matemática e Educação Matemática: compreensões dialogadas. Juiz de Fora: UFJF, 2010.

DAVÍDOV, Vasili Vasilievich. La enseñanza escolar y el desarrollo psíquico: investgación psicológica y exprimenal. Moscou: Progreso, 1988

DEMO, Pedro. Introdução à metodologia da ciência. 3. ed. São Paulo: Atlas, 1995.

FIALHO, Roberto Paulo Ribas. A matemática do sensível pelas mãos do artesão: marcas da aprendizagem matemática e da cultura material dos ceramistas de Icoaraci. 2013. Tese (Doutorado em Educação em Ciências e Matemáticas) - Instituto de Educação Matemática e Científica do Pará, Belém, 2013. 
FIORENTINI, Dario. Rumos da pesquisa brasileira em educação matemática: o caso da produção científica em cursos de pós-graduação. 1994. Tese (Doutorado em Educação) faculdade de Educação da Universidade Estadual de Campinas, Campinas, 1994.

FLORES, Cláudia Regina. Arte e visualidade: outros olhares para a visualização matemática. Seminário de Pesquisa, Programa de Pós-graduação em Educação Matemática, PUC-SP, março, 2016.

GÓES, Maria Cecília Rafael de; CRUZ, Maria Nazaré. Sentido, significado e conceito: notas sobre as contribuições de Lev Vigotski. Pró-Posições, Campinas, 17, p. 31-45, 2006.

GONZÁLEZ REY, Fernando. As categorias de sentido, sentido pessoal e sentido subjetivo: sua evolução e diferenciação na teoria histórico-cultural. Psic. da Ed., São Paulo, 24, p. 155-179, 2007.

GUSMÃO, Lucimar Donizete. Educação matemática pela arte: uma defesa da educação da sensibilidade no campo da matemática. 2013. Dissertação (Mestrado em Educação, Ciências e Matemática) - Universidade Federal do Paraná, Curitiba, 2013.

LEONTIEV, Alexei. O desenvolvimento do psiquismo. Lisboa: Horizonte Universitário, 1978.

LIBÂNEO, José Carlos; FREITAS, Raquel Marra da Madeira. Abstração, generalização e formação de conceitos como procedimentos intelectuais no processo de ensino e aprendizagem. In: LONGAREZI, Andréa Maturano; PUENTES, Roberto Valdés. O Sistema Elkonin-Davidov. Campinas: Mercado de Letras, 2020, p. 213-240.

LOPES, Anemari Roesler Luersen Vieira; et al. Trabalho coletivo e organização do ensino de matemática: princípios e práticas. Revista Zetetike, Campinas, SP, v. 24, p. 13-28, 2016.

MOURA, Manoel Oriosvaldo. A atividade de ensino como ação formadora. In: CASTRO, A. D.; CARVALHO, A. M. P. (Org.). Ensinar a ensinar: didática para a escola fundamental e média. São Paulo: Pioneira Thompson Learning, 2002.

MOURA, Manoel Oriosvaldo de; et al. Atividade orientadora de ensino: unidade entre ensino e aprendizagem. Revista Diálogo Educacional, Curitiba, v. 10, p. 205-229, 2010.

MINAYO, Maria Cecília de Souza (org.) Pesquisa social: teoria, método e criatividade. 22. ed. Rio de Janeiro: Vozes, 2003.

NOVAK, Joseph D. Learning, creating and using knowledge concept maps as facilitative tools in schools and coporations. Mahwah, NJ: Lawrense Erlbaun Associates, 1998.

ROLIM, Carmem Lúcia Artioli, GÓES, Maria Cecília Rafael. Crianças com câncer e o atendimento educacional nos ambientes hospitalar e escolar. Educação e Pesquisa, São Paulo, v. 35, n. 3, p. 509-523, set/dez. 2009.

READ, Herbert. A redenção do robô: meu encontro com a educação através da arte. Trad. Fernando Nuno. São Paulo: Summus, 1986.

RUIZ, João Álvaro. Metodologia científica: guia para eficiência nos estudos. 6. ed. São Paulo: Atlas, 2008. 
SADOVSKY, Patrícia. 0 ensino da matemática hoje: enfoques, sentidos e desafios. Trad. de Antônio de Padua Danese. São Paulo: Ática, 2010.

SAMAIN, Etienne. Como pensam as imagens. Campinas: Unicamp, 2012.

SANTOS. Vinícius de Macedo. Ensino da matemática na escola de nove anos: dúvidas, dividas e desafios. São Paulo: Cengage Learning, 2014.

SKOVSMOSE, Ole. Educação Crítica: incertezas, matemática, responsabilidade. São Paulo: Cortez, 2007.

TORISU, Edmilson Minoru. Sentidos e significados por um grupo de estudantes às tarefas matemáticas. Zetetiké, Campinas, v. 26, n. 2, 2018, p. 390-403.

VIGOTSKI, Lev Seminovich. Pensamento e palavra. In: VIGOTSK, L. S. A construção do pensamento e da linguagem. Trad. de Paulo Bezzera. São Paulo: Martins Fontes, 2001. p. 395-486. 